\title{
o Código de Defesa do Consumidor e os Contratos de Prestação de Serviços Educacionais*
}

\author{
Caxlos ORobexto Orabosa Olloxeixa \\ Advogado, Professor de Direito Civil na PUC/RJ
}

\section{Introdução}

4.

o contrário do que se passa com outros contratos (especialmente os de locação predial urbana para fins residenciais e aqueles envolvendo a concessão de créditos bancários), parece não haver a menor dúvida de que se encontram regidos pelo Código de Defesa do Consumidor os contratos cujo objeto reside na prestação remunerada de serviços de educação, aí compreendidos desde as atividades de ensino desenvolvidas por instituições permanentes (colégios, universidades, cursos de idiomas, academias de ginástica e balé, etc.) até as realizadas por profissionais autônomos (aulas particulares). Em qualquer desses casos, estarão presentes os personagens da relação jurídica de consumo, indicados nos arts. $2^{\circ}$ e $3^{\circ}$ da Lei $n^{\circ} 8.078 /$ 90: de um lado, o consumidor, o qual, em decorrência da definição ampla adotada no direito brasileiro, será tanto o próprio aluno (usuário do serviço), quanto aquele que houver contratado, como os pais e tutores; de outro lado, o fornecedor, pessoa física ou jurídica (e até mesmo - por que não? os chamados "entes despersonalizados", como uma sociedade de fato que explore atividades docentes), que se tenha obrigado a prestar serviços daquela natureza.

Oportuno registrar que, conquanto o tema não suscitasse controvérsia, a Lei no 8.170/91, a qual estabelecia regras para a fixação dos encargos educacionais, referentes ao ensino nos estabelecimentos particulares de nível pré-escolar, fundamental, médio e superior, dispôs, expressamente, que, "no caso de celebração de contratos de prestação de serviços educacionais, os mesmos deverão obedecer o disposto na Lei no 8.078 , de 11 de setembro de 1990 - Código de Defesa do Consumidor" (art. $3^{\circ}$ ).

Texto (com ligeiras modificaçōes e acrescido de notas) destinado aos anais do X Curso Brasilcon de Direito do Consumidor, realizado na Universidade do Estado do Rio de Janeiro (setembro de 1996). 
Tratava-se de uma dentre muitas daquelas normas que apenas... chovem no molhado. Sua revogação - originalmente, pela Medida Provisória $\mathrm{n}^{\mathrm{0}}$ 932, de 10 de março de 1995 (art. 14), em dispositivo repetido em suas versões posteriores, das quais a Medida Provisória $\mathrm{n}^{\mathrm{0}} 1.477$, de 04 de julho de 1996 (art. 12), é a que se encontra em vigor na data em que se escrevem estas notas - em nada afetou a incidência do Código àqueles contratos.

\section{Informação devida ao consumidor de serviços educacionais; proteção contra a propaganda enganosa; vinculação da oferta}

Disciplinada pelas normas do Código, a relação jurídica originada pelo contrato de prestação de serviços educacionais atribui a cada uma das partes envolvidas os direitos e deveres previstos na lei e no próprio negócio jurídico. Aliás, cabe recordar que a atuação do sistema legal de proteção ao consumidor se inicia antes mesmo da efetiva contratação, tutelando os interesses do potencial consumidor (isto é, daquele que, embora não tendo ainda contratado a prestação do serviço - e que, por isso, não se enquadre na definição do art. $2^{\circ}-$, possa, em tese, vir a fazê-lo): como deixa claro o art. 29 da Lei no $8.078 / 90$, os dispositivos referentes às "práticas abusivas", inseridos em seu Capítulo V, e os que concernem à "proteção contratual", presentes no Capítulo VI, incidem em benefício de "todas as pessoas determináveis ou não, expostas às práticas nele (sic) previstas". No dizer de autorizado intérprete do Código, "o que se exige é a simples exposição à prática, mesmo que não se consiga apontar, concretamente, um consumidor que esteja em vias de adquirir ou utilizar o produto ou serviço". ${ }^{1}$ sagrada em favor de potenciais consumidores, algumas interessantes hipóteses têm sido registradas na doutrina e nos repertórios de jurisprudência, relativas à prestação

Em substancioso estudo ${ }^{2}$, a Professora JUDITH MARTINS COSTA analisou espécie curiosa, na qual certo estabelecimento de ensino de segundo grau fizera veicular, em jornal capixaba, publicidade cujo conteúdo, embora rigorosamente verídico, poderia, contudo, induzir o leitor da mensagem a uma falsa conclusão. $O$ caso foi assim descrito: "... o Colégio Salesiano, a pretexto de homenagear o estudante André Luiz Domingues, seu antigo aluno entre a 5 a série do segundo grau e o primeiro científico, divulgou, em texto graficamente destacado, o fato de ter o mesmo obtido o primeiro lugar geral no vestibular da Universidade Federal do Espírito Santo - graficamente também destacando a sua experiência em '30 anos de vestibular', em texto colocado
No terreno desta tutela prévia, conde serviços educacionais.

1. ANTÔNIO HERMAN BENJAMIN, Código Brasileiro de Defesa do Consumidor: Comentado pelos Autores do Anteprojeto, Forense Universitária, $3^{a}$ ed., 1993, p. 147, destacado no original.

2. A guerra do vestibular e a distinção entre publicidade enganosa e clandestina, in Revista de Direito do Consumidor, vol. 6, p. 219 e ss., também publicado sob o título "A ambigüidade das peças publicitárias e os princípios do Código de Defesa do Consumidor, in AJURIS, vol. 59 , p. 113 e ss. logo abaixo da indicação de seu nome e logotipo - e inserindo, entre ambos os textos, em letras de pouquíssimo destaque gráfico, a expres são do seu 'orgulho' com a vitória do ex-aluno que lá estudara pelo menos dois anos antes" (destacado no original). Pouco adiante, fica esclarecido que "o estudante vitorioso realizará os seus estudos pré-vestibulares em outra escola, o Colégio Darwin, onde estudará na segunda e terceira séries do segundo grau". Como facilmente se percebe, conquanto a mensagem não contivesse qualquer informação inexata (aqui, nem sequer seria lícito cogitar de publicidade "enganosa por omissão", de que trata o art. 37, § 3º , do Código, pois a instituição de ensino informava, corretamente, que o aluno já não mais integrava seu corpo discente, no ano da aprovação no vestibular), a apresentação gráfica dos vários elementos que a compunham induziria o leitor à suposição (incorreta) de que o estudante se preparara para o certame no próprio Colégio Salesiano. Na perfeita observação da Professora JUDITH MARTINS COSTA, além de o anúncio, tal como concebido, contrariar a norma do art. 36, caput - pois se pretendeu dissimular o que publicidade é com manifestação de cortesia, o que não (apenas) $e ́$, com a conseqüência de que a ambigüidade sobre a natureza da peça é, aqui, a primeira causa do engano -, foram igualmente violadas as regras proibitivas da publicidade enganosa, porquanto "se a maioria dos consumidores não costuma ler o que está grafado em letras pequenas nas peças pu-

blicitárias por ter a sua atenção visual atraída para os tipos gráficos maiores (...), no caso examinado mesmo o leitor do anúncio regularmente cauteloso estabeleceria imediatamente a relação entre o primeiro daqueles textos ("André Luiz Domingues, $1^{\circ}$ lugar geral da Ufes") e o segundo ("Salesiano, 30 anos de pré-vestibular *50 anos de vitória"). A ambigüidade da mensagem é a segunda causa do engano: (grifos no original).

O exemplo, portanto, é ilustrativo da utilidade prática da cláusula "por qualquer outro modo", presente na definição legal de publicidade enganosa (CDC, art. $37, \S 1^{\circ}$ ): o caráter enganoso da mensagem publicitária não decorre, necessariamente, daquilo que nela se afirma, ou daquilo que nela se oculta (publicidade enganosa por omissão), mas pode também originar-se da forma pela qual é apresentada à massa de potenciais consumidores, ainda que contenha somente informações verdadeiras e não omita "dado essencial do produto ou serviço" (CDC, art. $\left.37, \S 3^{\circ}\right)$. Na correta advertência de Jaime Delgado Zegarra, una afirmación que en sí misma es verdadera puede resultar engañosa para el público em relación com el contexto publicitario en que se transmite, pois para analizar un anuncio hay que tomar en cuenta todos sus elementos y el efecto de conjunto, y no aisladamente una frase o una imagem. Podría resultar que cada uno de sus elementos sea inofensivo considerado individualmente, pero unido a los otros, en ciertos casos genera un concepto errado en el público. ${ }^{3}$

3. Defensa de los Consumidores de Productos y Servicios, coletânea organizada por GABRIEL STIGLITZ, Ediciones La Rocca, Buenos Aires, 1994, p. 158. Em lição substancialmente idêntica, afirma FÁBIO ULHOA COELHO que "a mensagem veiculada pelo anúncio deve ser também examinada mais detidamente, para se caracterizar a publicidade como enganosa. Anote-se, em primeiro lugar, que o potencial de indução em erro deve necessariamente decorrer do exame da peça publicitária como um todo.

Revista da Faculdade de Direito da UFRGS, v. 13, 1997 
Outro caso interessante, decidido pelo Juizado Especial de Bauru (SP), que também guarda relação com o dever de prévia informação ao consumidor, está regis trado na Revista de Direito do Consumidor, vol. 3. p. 220 e ss.: um casal e sua filha matricularam-se em curso de inglês, "oferecido com método diferenciado de aprendizagem, para turmas de três alunos, pois tinham interesse em fazer juntos, os três, referido curso". Paga uma importância inicial, os consumidores submeteram-se a uma "entrevista de avaliação", tomando conhecimento, apenas nessa oportunidade, que "não podiam freqüentar o curso juntos, na mesma turma". Desinteressando-se do curso, por causa da restrição que não lhes fora anteriormente exposta, os alunos pretenderam obter, sem sucesso, a devolu ção do que haviam pago. A hipótese - embora ali decidida também à luz de outros princípios - põe em destaque uma das mais relevantes normas do Código, segundo a qual "os contratos que regulam as relações de consumo não obrigarão os consumidores, se não lhes for dada a oportunidade de tomar conhecimento prévio de seu conteúdo ..." (art. 46, destacamos). Embora o fornecedor pudesse ter bons motivos, até de índole didática, para rejeitar a inclusão, na mesma turma, de três alunos pertencentes a uma só família, obviamente que tal informação deveria ter sido prestada aos consumidores até o momento da contratação, e não posteriormente. O pagamento da importância inicial, antes da "entrevista de avaliação", assinala o instante da celebração do contrato, a partir do qual só seria lícito incluir suprimir ou alterar cláusulas mediante 0 consentimento de todos os contratantes.

Tem inegável importância prática, de igual modo, o art. 30 do Código, segundo o qual "toda informação ou publicidade, suficientemente precisa, veiculada por qualquer forma ou meio de comunicação com relação a produtos e serviços oferecidos ou apresentados, obriga o fornecedor que a fizer veicular ou dela se utilizar e integra o contrato que vier a ser celebrado". Ora, no mercado de serviços educacionais, freqüentes são as chamadas publicitárias através das quais se exaltam, por exemplo, as características do estabelecimento educacional e as comodidades postas à disposição dos alunos (veiculam-se imagens de quadras para a prática de esportes, piscina, salas de aula dotadas de computadores, etc.) ou a qualificação profissional do corpo docente (transmitem-se mensagens como "nossos professores são formados em universidades estrangeiras"). No terreno dos contratos para aulas particulares, semelhante prática é corriqueira, bastando ao observador fothear os cadernos de classificados de qualquer dos grandes jornais cariocas ("Aulas

Mesmo a publicidade literalmente verdadeira pode ser tida por enganosa se, globalmente considerada, puder induzir o consumidor em erro. Como afirmava um extraordinário anúncio de TV do jornal Folha de São Paulo (no qual frases verdadeiras e aparentemente positivas acerca da realidade econômica e política da Alemanha interguerras acompanhavam a construção pontual do retrato de Hitter), pode-se mentir falando apenas verdades. Por certo, uma vez provando o empresário que as informaçöes veiculadas em sua publicidade, isolada e globalmente consideradas, revelam-se verdadeiras, entâo não se verifica o ilícito da enganosidade" ("A publicidade enganosa no Código de Defesa do Consumidor", in Revista de Direito do Consumidor, vol. 8 , p. 69 e ss., encontrando-se o trecho aqui reproduzido na p. 73, com destaque nosso).

Francês - professor com Baccalaureat em filosofia e letras", "Inglês - Professor com Doutorado", "Aulas de pintura - Formado em Belas Artes"). Quando se trata de aulas de idiomas estrangeiros, costuma-se ressal tar a nacionalidade de quem anuncia ("Ale mão professor nativo", "Francês ensina francês"), certamente porque, nesta hipótese, tal elemento pode exercer preponderante influência sobre o consumidor na escolha do prestador do serviço oferecido (presume-se que um estrangeiro conheça $\mathrm{e}$ fale sua língua melhor do que um brasileiro que a tenha estudado). Em qualquer desses casos, vincula-se o fornecedor aos termo da oferta, a qual "integra o contrato que vie a ser celebrado" (art. 30, in fine), de tal sorte que a eventual desconformidade entre ela e o serviço efetivamente prestado (consideradas as reais características do estabelecimento de ensino ou do professor) configurará vício da prestação (art. 20) ${ }^{4}$ abrindo-se ao consumidor a possibilidade de pleitear seja a rescisão do contrato e a restituição do que pagou, seja (se lhes in- teressar, ainda assim, a prestação, a despeito da divergência entre os termos da oferta e a realidade) o abatimento proporcional do preço (art. 20, no II e III) ${ }^{5}$. É o que acontecerá, por exemplo, se o colégio não apresentar as características anunciadas na mensagem publicitária, ou se o professor, que se intitulava estrangeiro, for nacional, ou desprovido da titulação acadêmica de que se dizia portador.

Acrescente-se que, incorporada ao contrato aquela informação ou publicidade "suficientemente precisa", será de todo irrelevante a circunstância de o instrumento contratual, concretamente firmado pelas partes, deixar de repetir, em cláusula específica, o que o fornecedor previamente anunciará; e se o contrato contiver estipulação contrária, incidirá a regra do art. 47 do Código, segundo a qual "as cláusulas contratuais serão interpretadas de maneira mais favorável ao consumidor", pois, nesta hipótese, haverá, simultaneamente, duas cláusulas distintas (aquela constante da publicidade ou informação e a que houver sido

4. Embora a norma do art. 30 encontre, aparentemente, na do art. 35 a previsão das sançöes ao seu descumprimento (e o intérprete será naturalmente induzido a essa conclusão, porque ambas foram reunidas na mesma Seçăo de um único Capítulo), certo e que o descompasso entre o teor da mensagem transmitida ao consumidor e a prestaçáo colocada à sua disposiçăo pode caracterizar o vício de qualidade do serviço, regulado no art. 20, o qual alude expressamente aos vicios "decorrentes da disparidade com as indicacōes constantes da oferta ou mensagem publicitárian: neste sentido, CLÁUDIA LIMA MARQUES, Contratos no Código de Defesa do Consumidor, RT, $2^{\mathrm{a}}$ ed, 1995, p. 232 e 241 (onde a autora cuida especificamente dos vícios de qualidade de produtos, em lição aplicável, mutatis mutandis, à hipótese aqui tratada) e PAULO LUIZ NETO LOBO, "Responsabilidade por vícios nas relaçōes de consumo", in Revista de Direito do Consumidor, vol. 14, p. 33 e ss. (acerca da questāo, p. 39).

5. Em muitos dos casos de que estamos tratando, estará logicamente excluída a possibilidade de o consumidor se valer da alternativa prevista no inciso I do art. 20 ("a reexecuçăo dos serviços, sem custo adicional"): assim, por exemplo, se não existir, no lugar da difusão da mensagem aos consumidores, outro estabelecimento de ensino, ou se ali não se encontrar quem esteja habilitado a assumir a mesma prestação "por conta e risco do fornecedor" (art. 20, $\left.\S 1^{2}\right)$. De tal solução, porém, será lícito cogitar na hipótese figurada por ZELMO DENARI, Código Brasileiro de Defesa do Consumidor, cit., p. 107: "Assim, se uma escola oferece um curso com um determinado conteúdo programático, o descumprimento do programa autoriza o aluno a pleitear a completitude da matéria, o que significa a reexecuçāo dos serviços educativos prestados (inc. I), sem prejuizo das sançōes previstas nos incs. II e III do dispositivo comentado".

Revista da Faculdade de Direito da UFRGS, v. 13, 1997 
estampada no instrumento) regulando, de diferente maneira, a mesma situação. ${ }^{6}$

\section{Responsabilidade por danos sofridos pelo consumidor durante a execução do contrato}

No que tange à tutela ressarcitória do consumidor, no campo dos contratos de prestação de serviços educacionais, vigoram os princípios do Código em matéria de responsabilidade do fornecedor, quer se cuide de fato, quer se trate de vício do serviço (respectivamente, arts. 14 e 20).

A responsabilidade do fornecedor pelo fato do serviço será, em regra, objetiva (art. 14, caput), ressalvada, contudo, a hipótese de prestação levada a efeito por profissional liberal (por exemplo, os professores que são diretamente contratados pelo consumidor para ministrar aulas particulares), pois, nesta última, o Código se manteve fiel ao sistema tradicional da responsabilidade subjetiva (art. 14, $\S 4^{\circ}$ ). Sobre o ponto, a jurisprudência registra acórdão que, de maneira correta, proclamou ser civilmente responsável, independentemente de culpa, "o estabelecimento de ensino por acidente sofrido pelo educando que se acha sob sua guarda e proteção" (in Revista de Direito do Consumidor, vol. 9, p. 156 e ss.). Conquanto a decisão, posterior à vigência da Lei $\mathrm{n}$ o $8.078 / 90$, não tenha situado o caso no cam- po da tutela ao consumidor (preferindo extrair da própria Constituição - art. 37, § 60 - o caráter objetivo da responsabilidade do réu), não pode haver dúvida quanto à incidência das normas do Código, sendo certo, portanto, que, se as tivesse invocado, o Tribunal de Alçada de Minas Gerais teria concluído de igual modo.

Sublinhe-se que, no tocante ao pos sível êxito das lições ministradas em instituições de ensino ou por professores particulares, os prestadores de serviços educacionais assumem obrigações de meio, e não de resultado, motivo pelo qual não terá o consumidor direito a qualquer indenização pleiteada, exemplificativamente, com fundamento no insucesso em concurso para o qual o aluno se preparará no estabelecimento do fornecedor.

\section{Cobrança de dívida: a questão das mensalidades escolares}

O Código proíbe, expressamente, o emprego de expedientes vexatórios, por parte do fornecedor, na cobrança de dívidas do consumidor: o art. 42 do Código dispõe, a propósito, que, quando inadimplente, o destinatário final de produtos e serviços "não será exposto a ridículo, nem será submetido a qualquer tipo de constrangimento ou ameaça".
6. Durante a sessão conclusiva do evento para o qual este trabalho foi escrito, houve quem colocasse em dúvida a utilidade do dispositivo, sob 0 argumento de que só se poderia cogitar de sua incidência na hipótese de cláusulas ambíguas. A crítica, todavia, é improcedente: é possível que tanto a mensagem publicitária, quanto a cláusula inserida no documento contratual sejam, ambas, extremamente claras, se isoladamente consideradas . Como 0 art. 30 determina a incorporaçăo da primeira ao texto do contrato, caberá ao intérprete aplicar aquela "mais favorável ao consumidor", ainda que a outra não ofereça, em si mesma, qualquer dificuldade interpretativa.

Revista da Faculdade de Direito da UFRGS, v. 13, 1997
A questão da cobrança de mensalidades escolares em atraso tornou-se de grande interesse social: como informa oJornal do Brasil, em edição de 31 de julho de 1996, "o calote no pagamento das mensalidades escolares passou de $5 \%$ a $6 \%$, no ano passado, para $25 \%$ em média, este ano. Levantamento da Federação Interestadual de Escolas Particulares (Fiep), realizado nas principais cidades de 18 estados, mostra que a parcela de carnês atrasados há mais de três meses varia de $20 \%$ no Paraná, a $47 \%$ no Piauí, em relação ao total. No Rio, o índice é de $26 \%$ (...)" (matéria intitulada "Escola leva calote de $25 \%$ dos pais", p. 1).

A propósito do problema, registra-se divergência de julgados no tocante à seguinte indagação: pode o estabelecimento escolar, sob a alegação de estar inadimplente o aluno, impedir-lhe a realização de provas, ou se negar à emissão de documentos por ele solicitados, ou, ainda, adotar outras medidas restritivas análogas?

Invocando, com freqüência, dispositivos de natureza constitucional (arts. 5o, no XXXIV e 205 da Constituição Federal), alguns responderam negativamente à questão: Tribunal de Justiça de São Paulo, Revista dos Tribunais, 668/85, 670/71, 671/94, $686 / 103,700 / 67$; outros, afirmativamente, entendendo admissível a invocação, pelo fornecedor, da exceção de contrato não cumprido: Tribunal de Justiça de São Paulo, Revista dos Tribunais, 651/60, 691/96; Tribunal de Justiça do Paraná, Revista dos Tribunais, 684/136; Tribunal de Justiça de Santa Catarina, Revista dos Tribunais, 653/ 176.

Na Lei $n$ o 8.170/91, o problema se achava disciplinado no art. 4ㅇ. "São proibi- das a suspensão de provas escolares, a retenção de documentos de transferência ou o indeferimento das matrículas dos alunos cuja inadimplência não decorrer de encargos fixados definitivamente e reajustados nos termos desta Lei". A contrario sensu, permitia-se a imposição daquelas sanções se, fixadas ou reajustadas em harmonia com as regras dos arts. $1^{\circ}$ e $2^{\circ}$ do diploma, o aluno deixasse, porém, de pagar pontualmente as mensalidades.

$\mathrm{Na}$ data em que se escreve este trabalho, vige norma de conteúdo diverso: 0 art. $6^{\circ}$ da Medida Provisória $n^{\circ} 1.477$, de 04 de julho de 1996, assim estatui: "São proibidas a suspensão de provas escolares, a retenção de documentos escolares, inclusive os de transferência, ou a aplicação de quaisquer outras penalidades pedagógicas, por motivo de inadimplemento".

\section{As ações coletivas como mecanismo de controle das mensalidades escolares: a (controvertida) questão da legitimidade do Ministério Público}

A sucessão dos diferentes critérios legais para a fixação e reajuste das mensalidades escolares, impostos ao longo dos últimos anos, e as várias dúvidas que tal legislação suscitava provocaram o ajuizamento de muitas ações contra os fornecedores de serviços educacionais. Em al. guns casos, o Ministério Público propôs ações civis públicas, visando a impedir aumentos abusivos das mensalidades escolares ou a coibir a imposição de sanções aos estudantes inadimplentes. Nesses proces- 
sos, acesa controvérsia se travou sobre a legitimação do Parquet para atuar em prol dos alunos, com reflexos na jurisprudência do próprio Superior Tribunal de Justiça, onde se registram acórdãos sustentando teses antagônicas (em sentido negativo: $\mathrm{Re}$ -

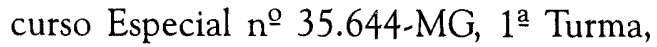
Relator Ministro Garcia Vieira, DJU de 22.11.93, e na Revista do Superior Tribunal de Justiça, 54/306; Recurso Especial no 47.019-MG, 1 a Turma, Relator Ministro César Asfor Rocha, DJU de 06.06.94, p. 14.254; Recurso Especial no 46.130-PR, 1른 Turma, Relator Ministro Demócrito Reinaldo, DJU de 20.06.94, p. 16.062; em sentido afirmativo: Recurso Especial no 38.176-MG, 4a Turma, in Revista dos Tribunais, 723/283; Recurso Especial no 84.599 . SC, 4a Turma, Relator Ministro Barros Monteiro, DJU de 10.06.96, p. 20.342). ${ }^{7}$

A vexata quaestio envolve, em realidade, diferentes indagações. Nos acórdãos do Superior Tribunal de Justiça desfavoráveis à atuação do Ministério Público, sustentou-se, nitidamente, a idéia de que se

7. Nos três casos decididos pela $1^{\mathrm{a}}$ Turma e no primeiro dentre os dois indicados precedentes da $4^{\mathrm{a}} \mathrm{Turma}$, cuidava-se de açōes sobre aumentos de mensalidades; no último dos acórdãos citados no texto, a açáo civil pública fora ajuizada para "fazer cessar sobre aumentos de mensalidades; no ulltmo dos acordáos citados no lexto, a açáo civil publica tora ajuizada para tazer cessar as restriçōes incidentes sobre alunos, cujos pais vinham discutindo com o estabelecimento acerca do montante das mensalidades escolares", com isso possibilitando "aos estudantes, nominados na inicial, a realizaçăo de provas e testes, fornecendo-thes as respectivas notas, bem como os boletins, incluindo seus nomes nas listas de chamada e, entregando, afinal, os documentos necessários a transferência àqueles que a requereram" (trechos do relatório do Ministro BARROS MONTEIRO). A questão da egitimidade ativa do Ministério Público, em ambas as hipóteses, é, porém, idêntica. Veja-se, ainda, sobre a matéria, o acórdão do Tribunal de Alçada do Paraná, in Revista de Direito do Consumidor, vol. 18, p. 198 e ss., no qual se qualificou como individuais homogêneos os interesses de pais de alunos em obter a revisão de mensalidades escolares, admitindo-se a legitimação do Ministério Público.

8. O citado acórdăo no Resp. no 84.599 - SC, em relaçăo ao tema ali versado (cessaçăo de restriçóes impostas a determinado grupo de alunos), entendeu que a hipótese era de interesses coletivos, qualificação igualmente adotada no acórdăo proferido no Resp. $n^{2} 38.176-M G$, que cuidava do problema da fixação das mensalidades. Ousamos divergir dessa qualificação, pelos argu-

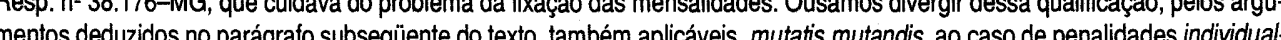
mente impostas a vários estudantes.

9. Contra, enquadrando o caso entre os de direitos coletivos, NELSON NERY JÚNIOR, Código Brasileiro de Defesa do Consumidor, cit., p. 620 ess.

Revista da Faculdade de Direito da UFRGS, v. 13, 1997 valor de suas mensalidades de acordo com certo critério, contestado por grande número de pais de alunos, que o reputam ile. gal. O fornecedor persiste na aplicação de seu próprio critério; porém, quanto às mensalidades dos filhos de A, B e C (a quem o dono do colégio, por um motivo qualquer, pretende agradar), aceita adotar o critério pretendido pela comunidade de pais. Percebe-se, aí, com grande facilidade, uma situação na qual, simultaneamente, os direitos de uns estarão sendo respeitados, enquanto os de todos os demais, lesados. Não se configura, portanto, aquela situação descrita como de "comunhão tipificada pelo fato de a satisfação de um só implica por força a satisfação de todos, assim como a lesão de um só constitui, ispo facto, lesão da inteira coletividade". ${ }^{10}$

Partindo-se, então, da premissa de que tais hipóteses envolvam interesses individuais homogêneos, pergunta-se: estará o Ministério Público legitimado à propositura da ação civil pública, conquanto o art. 129, nº III, da Constituição somente aluda a interesses difusos e coletivos?

Alguns dos mais autorizados intérpretes do Código têm respondido afirmativamente à questão, sob o argumento de que a própria Constituição, no art. 129, no IX, possibilitou ao legislador ordinário a atri- buição de outras funções ao Parquet, o que efetivamente teria ocorrido com a edição da Lei n⿳0 8.078/90 (art. 82, n I) (ADA PELLEGRINI GRINOVER, parecer in O Processo em evolução, Forense Universitária, $1^{\text {a }}$ ed., 1996, p. 423 e ss., também publicado na Revista de Direito do Consumidor, vol. 5, p. 206 e ss.: NELSON NERY JÚNIOR, Código Brasileiro de Defesa do Consumidor, cit., p. 627; TUPINAMBÁ MIGUEL CAS. TRO DO NASCIMENTO, Comentários ao Código do Consumidor, Aide, 3a ed., 1991, p. 105; RODOLFO DE CAMARGO MANCUSO, Manual do Consumidor em Juízo, Saraiva, 1994, p. 23). Não há, contudo, unanimidade (GALENO LACERDA, parecer publicado na Revista Forense, 333/ 193; ROGÉRIO LAURIA TUCCI, "Ação civil pública e sua abusiva utilização pelo Ministério Público", in Ajuris, vol. 56, p. 35 e ss., especialmente p. 51/52, onde se indica acórdão do Tribunal de Justiça de São Paulo que considerou Ministério Público parte ilegítima para ajuizar ação civil pública visando a obstar a majoração de preços de serviços prestados por estabelecimentos de ensino).

Como a questão envolve a exegese do texto constitucional, é possível imaginar que, mais cedo ou mais tarde, será convocado a resolvê-la o Supremo Tribunal Federal.

10. JOSÉ CARLOS BARBOSA MOREIRA, Temas de Direito Processual Civil (3a Série), Saraiva, 1984, p. 184. 